\title{
Self medicated Combiflam induced acute dermatological drug reaction
}

\author{
Harminder Singh*, Ritu Bala, Kamalpreet Kaur
}

Department of Pharmacology, GGS Medical College, Faridkot-151203, Punjab, India

Received: 20 August 2013

Accepted: 3 September 2013

\section{*Correspondence to:}

Dr. Harminder Singh,

Email:

dr_harminderchahal@ @rediffmail.com

(C) 2013 Singh H et al. This is an openaccess article distributed under the terms of the Creative Commons Attribution Non-Commercial License, which permits unrestricted noncommercial use, distribution, and reproduction in any medium, provided the original work is properly cited.

\begin{abstract}
A 30 year old female took a single tablet of Combiflam (ibuprofen $400 \mathrm{mg}+$ paracetamol $325 \mathrm{mg}$ ) for backache following which she noticed maculopapular rashes with generalized facial and lip swelling with generalized itching. Subsequently patient was treated with antihistaminic and steroids and she responded well. The causality assessment according to Naranjo casualty assessment scale come under "Probable" category of adverse drug reaction. According to World Health Organization-Uppsala Monitoring Centre causality assessment scale it falls under "Probable/Likely" category. According to Hartweig and Siegel severity assessment scale it was level 3 and moderate adverse drug reaction. This is a rare adverse effect of combiflam with the incidence less than $0.1 \%$. The awareness of the health care personnel to this widely used drug on its rare adverse effect is necessary.
\end{abstract}

Keywords: Combiflam, Ibuprofen, Paracetamol, Skin rash

\section{INTRODUCTION}

The prevalence of hypersensitivity to Nonsteroidal antiinflammatory drugs (NSAIDs) has been estimated to be 0.5 to $1.9 \%$ of the general population, whereas NSAIDs are responsible for 21 to $25 \%$ of all adverse reactions to drugs. ${ }^{1}$ Combiflam is a combination of ibuprofen $400 \mathrm{mg}$ plus paracetamol $325 \mathrm{mg}$ and widely used analgesics, antipyretics and anti-inflammatory drug. Although both drugs are readily available as over the counter (OTC) medications, they are also available on prescription. Although NSAIDs such as ibuprofen and paracetamol are generally well tolerated, infrequent but potential adverse effects include upper gastrointestinal mucosal damage, dyspepsia, nausea, vomiting, gastrointestinal bleeding, hypersensitivity and rarely renal failure and heart failure. ${ }^{2}$

Combiflam is a NSAID, in pharmacologic studies; combiflam has shown anti-inflammatory, analgesic, and antipyretic activity. As with other NSAIDs, its mode of action is inhibition of enzyme cyclooxygenase, involved in its anti-inflammatory activity, as well as contributes to its efficacy in relieving pain related to inflammation, especially rheumatic disorders.
The most common adverse effects of this drug are gastritis, peptic ulceration, and depression of renal function, all of which result primarily from prostaglandin inhibition. ${ }^{3}$

Dermatologic disorder is an important but rare adverse effect of NSAID. Mahboob and Haroon, 1998 reported a retrospective study on the fix drug eruption cases and revealed that ibuprofen is a drug which can present this adverse effect. Indeed, a wide spectrum of dermatologic disorder among ibuprofen users has been reported. ${ }^{4-6}$

Here, we are reporting a case of maculopapular dermatological eruption, generalized facial and lip swelling and itching all over the body especially extremities following self medicated single fixed dose of "combiflam".

\section{CASE REPORT}

A 30 year old female had backache with headache for 5-6 hours for which she took a single tablet of Combiflam (ibuprofen $400 \mathrm{mg}+$ paracetamol $325 \mathrm{mg}$ with expiry date of 2015) ${ }^{7}$ at night around 11PM following which she noticed maculopapular rashes with generalized facial and lip swelling in early morning at around 3AM (Figure 1). At around 6AM she also experienced generalized itching on both her forearms which gradually spread all over the 
limbs, trunk, abdomen sparing palms and soles. No histories of other concomitant drugs usage were reported. There is no significant allergy from any food or with any cosmetic products. On general examination, patient vitals were stable with blood pressure $120 / 80 \mathrm{~mm}$ of mercury and pulse rate 90/min, regular. On local dermatological examination, a maculopapular rash on forehead, dorsum of hand, extensor surface of forearms, front and back of trunk and abdomen, whole of lower limbs excluding palms and soles was noticed. For this acute drug reaction management, she rushed to the casualty department of a local hospital where she was treated with injection dexamethasone (4 mg) and injection pheniramine $(22.5 \mathrm{mg})$ intravenously and intramuscularly respectively and sign and symptoms subsided within a span of next 24 hours.

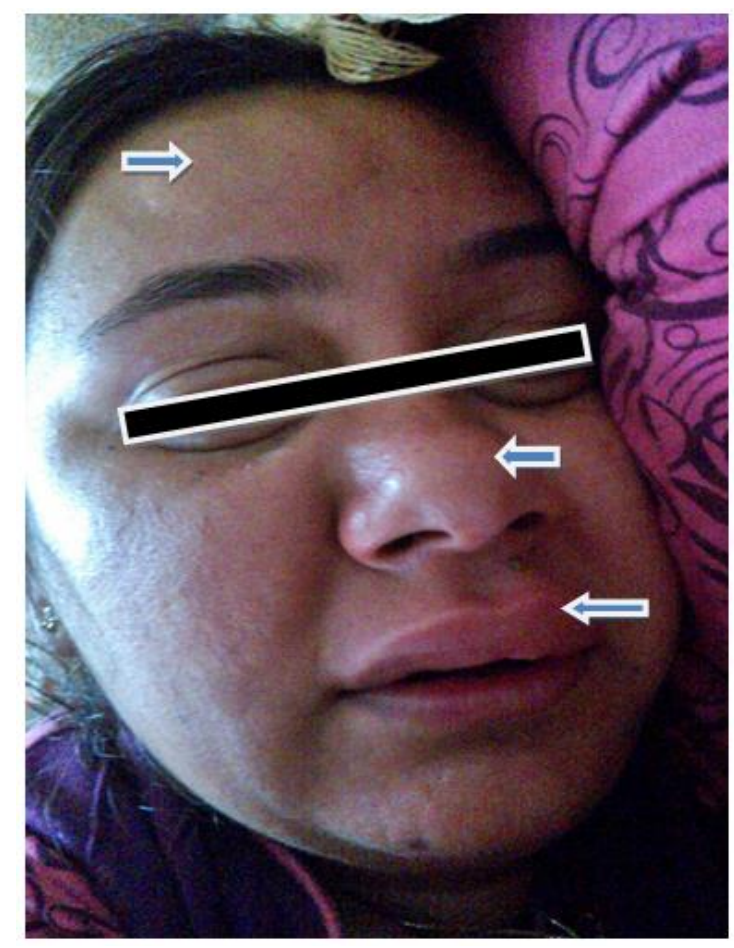

Figure 1: Maculopapular rashes with generalized facial and lip swelling.

\section{DISCUSSION}

The dermatological reaction of combiflam as pruritus is described in less than $1 \%$ of the patients. However, the skin eruption as Urticaria, erythema is more infrequent (less than 0.1). ${ }^{8}$ In very serious case, the Steven Johnson syndrome and can be detected. ${ }^{6}$

The causality assessment according to Naranjo causality assessment scale is 8 which put it under "Probable" category of adverse drug reaction. ${ }^{9}$ According to World Health Organization-Uppsala Monitoring Centre causality assessment scale it falls under "Probable/Likely" category of adverse drug reaction. ${ }^{10}$ According to Hartweig and Siegel severity assessment scale it was level 3 and moderate adverse drug reaction. ${ }^{11}$ Written informed consent to report the above mentioned case report was obtained from the patient.

A single tablet of Combiflam is a fixed dose combination containing ibuprofen in a dose of $400 \mathrm{mg}$ and paracetamol in a dose of $325 \mathrm{mg}$. It is an extensively used as OTC analgesic and anti- inflammatory drug. There are case reports showing that both ibuprofen and paracetamol can cause skin rashes as adverse drug reaction. ${ }^{12}$ But this is a rare event with either of the drug with incidence less than $0.1 \%$ for ibuprofen and incidence for paracetamol is not known. ${ }^{4}$

However, we did not perform any skin test or specific immunological test (IgE etc) and the main differential diagnosis is the herpes oralis, which presented as the lip lesion and usually accompanied with the erythema multiforme skin lesion. But in this case the lip lesion is not painful and can be used as a clue for exclusion of the herpes oralis.

\section{CONCLUSION}

We are reporting a probable rare case of combiflam related acute dermatological drug reaction. As Combiflam is a widely used as OTC analgesic and anti-inflammatory for various indications the health care personnel must be aware of this rare adverse drug reaction to this drug and keep it in mind when he/she encounters one.

\section{Funding: None \\ Conflict of interest: None declared \\ Ethical approval: Not required}

\section{REFERENCES}

1. Cornejo-Garcia JA, Blanca-López N, Doña I, Andreu I, Agúndez JA, Carballo $M$ et al. Hypersensitivity reactions to non-steroidal anti-inflammatory drugs. Curr Drug Metab 2009;10:971-80.

2. Hernandez-Diaz S, Garcia-Rodriguez LA. Epidemiologic assessment of the safety of conventional nonsteroidal anti-inflammatory drugs. Am J Med 2001;110:20S-27S.

3. Huskisson EC, Hart FD, Shenfield GM, Taylor RT. Ibuprofen. A review. Practitioner 1971;207:639-43.

4. Mahboob A, Haroon TS. Drugs causing fixed eruptions: a study of 450 cases. Int J Dermatol 1998;37:833-8.

5. Davidson KA, Ringpfeil F, Lee JB. Ibuprofen-induced bullous leukocytoclastic vasculitis. Cutis 2001;67:3037.

6. Sternlieb P, Robinson RM. Stevens-Johnson syndrome plus toxic hepatitis due to ibuprofen. N Y State J Med 1978;78:1239-43.

7. Grosser T, Smyth E, Fitzgerald GA. AntiInflammatory, Antipyretic, and Analgesic Agents; Pharmacotherapy of Gout. In: Brunton LL, ChabnerBA, Knollman BC, editors. Goodman \& 
Gilman's The pharmacological basis of therapeutics. 12th ed. New York: McGraw-Hill; 2011. p. 959-1004.

8. Cutaneous drug reaction case reports: from the world literature. Am J Clin Dermatol 2001;2:267-74.

9. Naranjo CA, Busto U, Sellers EM, Sandor P, Ruiz I, Roberts UA, et al. A Method for estimating theprobability of adverse drug reaction. Clin Pharamacol Ther 198;30:239-45.

10. WHO-UMC Causality Assessment Scale of Suspected Adverse Reactions. [Updated 2012 Apr 17]. Available from: www.who-umc.org [Last accessed on 2013 March].

11. Hartweig SC, Dengere SD, Schneider PJ. Severity indexed, incident report based medication error reporting program. Am J Hosp Pharm 1991;48:2611-6.

12. Sehgal VN. Paracetamol induced bilateral symmetric multiple fixed drug eruptions in a child. Pediatr Dermatol 1999;16:165-6.

doi:10.5455/2319-2003.ijbcp20131231

Cite this article as: Singh H, Bala R, Kaur K. Self medicated Combiflam induced acute dermatological drug reaction. Int J Basic Clin Pharmacol 2013;2:82830 . 